\title{
Uninsurable Individual Risk and the Cyclical Behavior of Unemployment and Vacancies *
}

\author{
Enchuan Shao ${ }^{\dagger}$ \\ University of Iowa
}

Pedro Silos

Federal Reserve Bank of Atlanta

February 8, 2007

\begin{abstract}
This paper is concerned with the business cycle dynamics in search and matching models of the labor market when agents are ex-post heterogeneous. We focus on wealth heterogeneity that comes as a result of imperfect opportunities to insure against idiosyncratic risk. We show that this heterogeneity implies wage rigidity relative to a complete insurance economy. The fraction of wealth poor agents prevents real wages from falling too much in recessions, since small decreases in income imply large losses in utility. Analogously, wages rise less in expansions compared to the standard model as small increases are enough for poor workers to accept job offers. This mechanism reduces the volatility of wages and increases the volatility of vacancies and unemployment. This channel can be relevant if the lack of insurance is large enough so that the fraction of agents close to the borrowing constraint is significant. However, discipline in the parameterization implies an earnings variance and a persistence in the unemployment state that results in a large degree of self insurance.
\end{abstract}

\footnotetext{
${ }^{*}$ Thanks to Matt Mitchell, Elena Pastorino, Galina Vereschagina, and especially B. Ravikumar, from whom we have received many useful comments. This paper was previously circulated with the title "Is Uninsurable Individual Risk Important for the Cyclical Behavior of Unemployment and Vacancies?"

${ }^{\dagger}$ Department of Economics, University of Iowa, Iowa City, IA 52245, tel: 319-335-1404 (phone), 319335-1956 (fax), enchuan-shao@uiowa.edu.

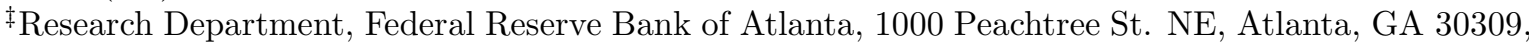
404-498-8630 (phone), 404-498-8956 (fax), Pedro.Silos@atl.frb.org
}

The views expressed here are the authors' and not necessarily those of the Federal Reserve Bank of Atlanta or the Federal Reserve System. 


\section{Introduction}

Shimer (2005) showed that a standard Mortensen-Pissarides search and matching model augmented with aggregate shocks generated a much lower volatility in the vacanciesto-unemployment $(V-U)$ ratio than that observed in the data. The empirical value is about 20 times as large as the value generated by the model. Search and matching models generate a non-trivial idiosyncratic employment risk, and as a result, potentially a large dispersion in asset holdings. Here we show that this heterogeneity in asset holdings acts as a device that smooths wage fluctuations. As it will become clearer below, when the negotiation of wages takes place, the fraction of agents close to or at the borrowing constraint prevents wages from falling too much during a recession: small decreases in the real wage imply large losses in utility. Analogously, during an expansion a mild increase in wages is enough for very poor agents to accept a job offer, as their utility increases substantially. Firms react by posting more vacancies during booms and fewer during expansions than they would otherwise. This mechanism is capable of increasing substantially the volatility of the $V-U$ ratio, and in fact, a model where agents are heterogeneous in their degree of patience can multiply the volatility of the $V-U$ ratio by a factor of four. However, too large a fraction of agents need to be borrowing constrained. We explore other features that prevent agents from smoothing out shocks effectively and show that in most reasonable parameterizations the introduction of uninsurable risk has a small quantitative effect, although the volatilities of the $V-U$ ratio and wages are closer to their empirical values relative to a full insurance economy.

The model economy we present is a version of the stochastic growth model with labor search and matching frictions. There is a representative firm that posts job vacancies, and workers search when they are unemployed, hoping to get matched to a job offer. Employed workers are at risk of losing their job and becoming unemployed. However, we assume that there is no insurance mechanism that can perfectly eliminate the employment risk: agents have to self insure using their holdings of physical capital only. Our results show that, quantitatively, the ability of agents to smooth consumption effectively is responsible for the similarity between the full insurance economy and the economies with idiosyncratic 
risk. Uninsurable risk helps, but it is not enough to bring the volatility of the $V-U$ ratio anywhere close to the data.

The reason for the negligible impact of introducing idiosyncratic risk is that, given the magnitude of shocks, the degree of self-insurance is remarkably good. This results in a very small fraction of agents close or at the borrowing constraint. This is consistent with Krusell and Smith's (1998) result, where the lack of perfect insurance in a version of the stochastic growth model generates too few poor agents and many rich individuals. The degree of persistence and variance in the employment-unemployment transitions is not enough to prevent people from smoothing out shocks effectively. Besides heterogeneity in the discount factors, we evaluate the effects of introducing (separately) the following features in the model: an irreversibility constraint on investment, a minimum consumption requirement, and different productivity levels across workers. All these versions improve relative to the full insurance economy. In some cases, the improvement is quite significant. For instance, assuming productivity shocks that affect workers can double the volatility of the $V-U$ ratio in comparison to the full insurance model.

There is by now a large literature on search and matching in the labor markets. Nevertheless, research that focuses on business cycles has not widely accepted the search model as the standard way of thinking about labor markets. There are exceptions such as Andolfatto (1993) and Merz (1995). These two examples assume that all workers belong to a household. In this household, some agents work and others search, but they all insure each other against being fired or not finding a job. Acemoglu and Shimer (1999) focus on the optimal unemployment insurance contract in a search environment with capital accumulation and where agents are risk averse. However, they do not introduce aggregate shocks. In a line of research more related to our paper, Rudanko (2006) builds an economy in which agents face idiosyncratic and aggregate shocks. She introduces search and matching frictions in the labor market, and long term contracts in wages where the firm provides insurance to the worker against drops in productivity. A key difference between hers and our paper is that there is no capital accumulation (or any form of savings) in her model. The worker consumes the wage and the unemployed consumes the 
unemployment benefit. As we show here, savings are key at explaining the inability of the presence of uninsurable risk to amplify aggregate fluctuations relative to the perfect insurance economy.

\section{The Model}

The model is a version of the one-sector stochastic growth model with labor market search frictions and where opportunities for perfect insurance are absent. There is a continuum of agents distributed uniformly on the unit interval. They are all endowed with one unit of time and maximize expected lifetime utility of consumption $E_{0} \sum_{t=0}^{\infty} \beta^{t} u\left(c_{t}\right)$, where $u$ satisfies the usual conditions and $\beta$ is a factor of time preference. Each agent faces different opportunities for exchanging labor services. In particular, individuals either have a job opportunity or not, and job opportunities arrive at random as is typical in the standard labor market search model. The absence of a full set of contingent claims implies that an agent's employment status determines his income. To smooth consumption across states and time, agents can only use physical capital and they are all endowed with $k_{0}$ of it to start with. The initial employment status is also given.

There is a continuum of risk neutral entrepreneurs who maximize $E_{0} \sum_{t=0}^{\infty} \beta^{t} \phi_{t}$, where $\phi$ is the sum of current period cash flows from firms that they own ${ }^{1}$. Firms use capital $K$ and labor $N$ to produce output $Y$ subject to a constant returns-to-scale production technology $Y=z F(K, N)$. The aggregate productivity $z$ of firms evolves according to a stochastic process known by agents.

In order to produce output, each job requires a worker. Let $N_{t}$ denote the number of jobs that are matched with a worker at the beginning of period $t$; hence, $N_{t}$ is the measure of current period employed workers and $1-N_{t}$ is the measure of unemployed workers currently available for work. Let $V_{t}$ denote the total number of new jobs made available by firms during period t. Following Pissarides (2001), the rate at which new job matches is governed by an aggregate matching technology, $M\left(V_{t}, 1-N_{t}\right)$, so that the

\footnotetext{
${ }^{1}$ In principle, $\phi_{t}$ could be negative. However, this was not the case in any of our simulations.
} 
employment evolves according to:

$$
N_{t+1}=\left(1-s_{t}\right) N_{t}+M_{t}
$$

where $s_{t} \in(0,1)$ is the exogenous separation rate of job-worker pairs at time $t$. The probability for a worker to find a job offer is $\pi_{t}=M\left(V_{t}, 1-N_{t}\right) /\left(1-N_{t}\right)$ and the probability for a firm to match a worker with a vacancy is $p_{t}=M\left(V_{t}, 1-N_{t}\right) / V_{t}$.

\subsection{Optimization}

The agents' employment status is determined by whether they successfully matched with a firm the previous period (in case they were unemployed) and whether they were exogenously separated (in case they were employed). This random matching and separation process induces different employment histories among agents and consequently leads to heterogeneous asset holdings. Let $Q_{t}(k, i)$ denote the joint distribution of individual capital holdings and employment status at period $t$. This cross-sectional distribution evolves according to the law of motion

$$
Q_{t+1}=H\left(Q_{t}, z_{t}\right)
$$

Let $\chi_{t} \equiv\left(z_{t}, Q_{t}\right)$ and $k_{t}$ be the set of state variables in the agents' problem, which involves choosing a level of consumption $c^{i}$, and saving $k^{i}$ contingent upon the agent's employment status $i$. The employment status can be $i=e$, which denotes working, or $i=u$, which denotes searching (or being unemployed). The measure of unemployed and employed workers can be obtained by integrating $Q$ over the appropriate type,

$$
\begin{aligned}
N_{t} & =\int_{i=e} d Q_{t}(k, i), \\
1-N_{t} & =\int_{i=u} d Q_{t}(k, i) .
\end{aligned}
$$

We now switch notation slightly and we will denote variables with no subscript to be current period variables and variables with a prime to be next period's variables. Denoting by $J^{e}$ the value function for an employed worker and $J^{u}$ the value function for an unemployed worker, the Bellman equation for an agent who works during the current 
period is:

$$
\begin{gathered}
J^{e}(k, \chi)=\max _{\left\{c^{e}, k^{e^{\prime}}\right\}} u\left(c^{e}\right)+\beta\left[(1-s) J^{e}\left(k^{e^{\prime}}, \chi^{\prime}\right)+s J^{u}\left(k^{e^{\prime}}, \chi^{\prime}\right)\right] \\
\text { s.t. } \quad c^{e}+k^{e^{\prime}}=w+R k+(1-\delta) k, \\
k^{e^{\prime}} \geq 0, Q^{\prime}=H(\chi) .
\end{gathered}
$$

The value function of the worker is determined by the wage she obtains the current period plus the capital income obtained by renting capital. The worker takes into account she might be unemployed tomorrow with probability $s$ and remain employed with probability $1-s$. The constraints in this optimization problem are the budget constraint for the employed worker, a non-negativity constraint for capital holdings, and a law of motion for the aggregate distribution of asset holdings. The wage rate $w$ is determined by a bargaining rule to be discussed later and the interest rate $R$ is determined in a competitive financial market.

Analogously the Bellman equation for an agent who searches the current period is:

$$
\begin{gathered}
J^{u}(k, \chi)=\max _{\left\{c^{u}, k^{u^{\prime}}\right\}} u\left(c^{u}\right)+\beta\left[(1-\pi) J^{u}\left(k^{u^{\prime}}, \chi\right)+\pi J^{e}\left(k^{u^{\prime}}, \chi^{\prime}\right)\right] \\
\text { s.t. } \quad c^{u}+k^{u^{\prime}}=R k+(1-\delta) k, \\
k^{i^{\prime}} \geq 0, Q^{\prime}=H(\chi) .
\end{gathered}
$$

An unemployed agent receives no benefits or any other sources of income besides capital income from her asset holdings. In her optimization problem, she conditions on the probability $\pi$ of being matched with a firm this period and working the following period and the probability of remaining unemployed $(1-\pi)$.

The ownership structure of firms and the constant returns-to-scale production technology allow us to only consider a representative firm which maximizes the present discounted value of the stream of future profits. A firm interested in filling an available job must undertake recruiting and screening activities, which are necessary for finding a suitable employee. Let $\omega$ denote the unitary cost of recruiting, the representative firm chooses a contingency plan $\left\{V_{t}, K_{t}\right\}_{t=0}^{\infty}$ that maximizes the expected discounted sum of cash flows. 
The Bellman equation for this maximization problem is:

$$
\begin{gathered}
W(\chi)=\max _{\left\{V, K_{d}\right\}}\left\{z K_{d}^{\alpha} N^{1-\alpha}-R K_{d}-w N-\omega V+\beta E W\left(\chi^{\prime}\right)\right\} \\
\text { s.t. } \quad N^{\prime}=(1-s) N+p V, \\
Q^{\prime}=H(\chi) .
\end{gathered}
$$

In the firm's Bellman equation we explicitly differentiate between the capital demanded by the firm, $K_{d}$, and the capital supplied by the individuals, implicit in the state vector $\chi$. After equating these two in equalibrium, the optimal choices for the firm are given by the following optimality conditions:

$$
\begin{aligned}
R & =\alpha z K^{\alpha-1} N^{1-\alpha} \\
\frac{\omega}{p} & =\beta E\left[(1-\alpha) z^{\prime} K^{\prime \alpha} N^{\prime-\alpha}-w^{\prime}+\frac{\omega(1-s)}{p^{\prime}}\right] .
\end{aligned}
$$

\subsection{Timing of Events}

1. At the beginning of period $t$, the aggregate productivity shock $z_{t}$ is revealed and publicly observed.

2. Goods and capital markets open.

(a) A representative firm rents capital from both types of agents (workers and searchers), uses $N_{t}$ units of labor to produce output, and posts new job vacancies $V_{t}$.

(b) The worker provides inelastic labor service to the firm and, in return, receives wage payments from the firm, which are determined by a bargaining rule. Besides labor income, the worker also receives interest payments on capital and makes consumption and investment decisions.

(c) The searcher receives no wage income and finances consumption and investment decisions with capital interest payments.

3. Goods and capital markets close and the labor market opens: 
(a) The unemployed individuals and the firm search in the labor market. If they are successfully matched a new job is created which will be filled the following period. The matching rate $\pi_{t}$ is i.i.d across all unemployed individuals.

(b) The employed agents might be separated from their current match with probability $s$. They must wait until the following period to search for work.

(c) The workers who remain employed and those who are successfully matched with the firm constitute a class of employed workers the following period.

4. The labor market closes.

\subsection{Wage Bargaining}

If bargaining occurs between the firm and each worker, the outcome will be an entire distribution of individual-specific wages. The purpose of this paper is not to understand wage dispersion or the dynamics of the income distribution, and therefore we assume that workers can form a labor union. The firm negotiates with the union rather than with individuals. The objective of the labor union is to maximize the aggregate surplus of all workers, which is given by,

$$
\begin{gathered}
\int\left[J^{e}(k, \chi)-J^{u}(k, \chi)\right] d Q= \\
N \int_{e}\left[J^{e}(k, \chi)-J^{u}(k, \chi)\right] d Q+(1-N) \int_{u}\left[J^{e}(k, \chi)-J^{u}(k, \chi)\right] d Q .
\end{gathered}
$$

In the previous expression the symbol $\int_{i}, i \in\{e, u\}$ means integrating over assets held only by either employed or unemployed agents. The marginal value of a match for the firm is $\partial W(\chi) / \partial N$. The wage solves the following Nash bargaining problem:

$$
\max _{w}\left(\frac{\partial W(\chi)}{\partial N}\right)^{\xi}\left(\int\left[J^{e}(k, \chi)-J^{u}(k, \chi)\right] d Q\right)^{1-\xi}
$$

where $\xi$ is the firm's bargaining power. The Nash bargaining solution can be summarized as

$$
\xi\left(\int\left[J^{e}(k, \chi)-J^{u}(k, \chi)\right] d Q\right)=(1-\xi) \tilde{\Lambda} \frac{\partial W(\chi)}{\partial N},
$$

where $\tilde{\Lambda}=N \int_{e} u^{\prime}\left(c^{e}(k, \chi)\right) d Q+\left(1-N_{t}\right) \int_{u} u^{\prime}\left(c^{u}(k, \chi)\right) d Q$ is the marginal payoff of being employed. 
The marginal value of employment for the firm can be obtained from (7) and (8),

$$
\frac{\partial W(\chi)}{\partial N}=(1-\alpha) z K^{\alpha} N^{-\alpha}-w+\frac{\omega(1-s)}{p}
$$

Substituting (13) into (12), we have the wage equation

$$
w=(1-\alpha) z K^{\alpha} N^{-\alpha}+\frac{\omega(1-s)}{p}-\frac{\xi}{1-\xi} \frac{1}{\tilde{\Lambda}}\left(\int\left[J^{e}(k, \chi)-J^{u}(k, \chi)\right] d Q\right)
$$

Using (14) and (11), we can solve for the optimal job posting,

$$
\frac{\omega}{p}=\beta E\left[\frac{\xi}{1-\xi} \frac{1}{\tilde{\Lambda}^{\prime}}\left(\int\left[J^{e}(k, \chi)-J^{u}(k, \chi)\right] d Q^{\prime}\right)\right]
$$

\subsection{Equilibrium}

A recursive competitive equilibrium is a pair of price functions $R$ and $w$, the individuals's value functions $J^{u}(k, \chi)$ and $J^{e}(k, \chi)$, decision rules $k^{\prime}(k, \chi), c(k, \chi)$ and vacancies posted $V$, and a law of motion $H$ for $Q$ such that

1. Given prices, the number of job vacancies $V$ which determines the matching probability, and $H$, the value function solves the agents' optimization problem and the optimal decision rules are $k^{\prime}(k, \chi), c(k, \chi)$.

2. Given the decision rule $f$, the optimal job posting rule $V$ is determined by maximizing the firm's discounted present value of profits, i.e. V satisfies (15);

3. The interest rate $R$ satisfies (10) and the wage rate is a solution of Nash bargaining $(14)$;

4. The decision rule $f$ and the Markov processes for $z$ and s imply that today's distribution $Q$ is mapped into tomorrow's $Q^{\prime}$ by $H$;

5. Goods market must clear:

$$
\int c d Q+K^{\prime}-(1-\delta) K+\omega V=z K^{\alpha} N^{1-\alpha}
$$


As is typical in models with idiosyncratic and aggregate risk, one needs to avoid having the entire distribution $Q$ as a state variable in order to obtain quantitative results. As other examples in the literature, we followed Krusell and Smith (1998) and others in summarizing the distribution $Q$ by a vector of its moments $m$ and replacing $H$ by some polynomial that determines $m^{\prime}$ as a function of $m$. It turned out that, as in Krusell and Smith's case, the aggregate capital stock sufficed to summarize the entire distribution of capital holdings. For the interested reader, we provide a detailed description of our solution method and some computational subtleties in an Appendix.

\subsection{Full Insurance}

Suppose that workers live together in a very large extended family, called a household. There are a continuum of identical households in the economy, and their mass is normalized to 1. Each household member is perfectly insured by the other household members against variations in labor income due to employment status. The structure of goods and factors markets is identical to the idiosyncratic risk case. The household's problem can then be written as the following dynamic programming problem:

$$
\begin{gathered}
J(z, K, N)=\max _{C, K^{\prime}} u(C)+\beta E J\left(z^{\prime}, K^{\prime}, N^{\prime}\right), \\
\text { s.t. } \quad C+K^{\prime}=w N+(R+1-\delta) K, \\
N^{\prime}=N(1-s)+(1-N) \pi .
\end{gathered}
$$

The firm's problem remains the same as before. The wages are determined by the Nash bargaining. Hence the wage equation and the optimal job posting are given by:

$$
\begin{aligned}
w_{t} & =(1-\alpha) z K^{\alpha} N^{-\alpha}+\frac{\omega(1-s)}{p}-\frac{\xi}{1-\xi} \frac{1}{u^{\prime}(C)} \frac{\partial J(z, K, N)}{\partial N} \\
\frac{\omega}{p} & =\beta E\left[\frac{\xi}{1-\xi} \frac{1}{u^{\prime}\left(C^{\prime}\right)} \frac{\partial J\left(z^{\prime}, K^{\prime}, N^{\prime}\right)}{\partial N^{\prime}}\right]
\end{aligned}
$$

where $\partial J(z, K, N) / \partial N$ is the marginal value of employment for a household and is defined by:

$$
\frac{\partial J(z, K, N)}{\partial N}=u^{\prime}(c) w^{\prime}+\left(1-s^{\prime}-\pi\right) \beta E\left(\frac{\partial J\left(z^{\prime}, K^{\prime}, N^{\prime}\right)}{\partial N^{\prime}}\right)
$$




\section{Parameterization}

In choosing functional forms and parameter values we have either followed previous research or set parameters to match a few steady state moments.

Regarding preferences we chose the constant relative risk aversion as our per period utility function. This functional form is widely popular in the macroeconomics literature and its only parameter is the relative risk aversion coefficient $\sigma$ :

$$
u(c)=\frac{c^{1-\sigma}}{1-\sigma}
$$

The value for $\sigma$ that macroeconomists generally use, ranges from 1 to 4 . We have chosen 1.5 as the benchmark but provide some sensitivity analysis for changing that value. The agents' discount factor $\beta$ was set at 0.99 . This is the usual choice in infinite horizon economies modeled at the quarterly frequency. In a complete markets framework it implies an annual interest rate of approximately 4.2 percent.

The firm faces a Cobb-Douglas technology on capital and labor for producing output:

$$
Y=z K^{\alpha} N^{1-\alpha}
$$

Capital's share in national income has averaged about $36 \%$ for the US in the postwar period. As a result we set $\alpha$ to 0.36 . The autocorrelation and the variance of the total factor productivity shock $z_{t}$ are set to roughly match the observed persistence and variability of deviations from trend in the Solow residual. For simplicity we restrict $z_{t}$ to take on two values: 1.01 and 0.99 . The transition matrix that determines the stage of the business cycle is,

$$
\Pi=\left[\begin{array}{ll}
0.95 & 0.05 \\
0.05 & 0.95
\end{array}\right]
$$

We chose a Cobb-Douglas as the functional form for the matching technology. This is the most common choice in models of search and matching in labor markets.

$$
M(V, 1-N)=\mu V^{\gamma}(1-N)^{1-\gamma}
$$

The parameter $\gamma$ was set equal to $\xi$, the parameter driving the firm's bargaining power, which in complete markets models ensures that the allocation in the decentralized economy 
Table 1: Summary of Parameterization

\begin{tabular}{ccc} 
Parameter & Value & Target/Source \\
\hline \hline & & NIPA \\
$\alpha$ & 0.36 & $r \simeq 4.2 \%$ \\
$\beta$ & 0.99 & - \\
$s$ & 0.1 & Andolfatto $(1993)$ \\
$\sigma$ & 1.5 & $C / Y=0.75$ \\
$\xi$ & - & $w V / Y=0.03$ \\
$\mu$ & - & $V / U=12.1$ \\
$\delta$ & - & $\pi=0.62$ \\
$\omega$ & - &
\end{tabular}

is the same is in the social optimum. The parameters $\xi, \mu, \delta$ and $\omega$ were set so that they match four moments: a consumption-to-output ratio of 0.75 , a vacancy-cost-to-output ratio of about 0.03 , an average vacancy-unemployment ratio of 12.1 and a matching probability of approximately 0.62 .

Finally, the separation rate $s$ was set at 0.1 consistent with previous studies of labor search and business cycles. The following table summarizes the parameterization:

\section{Results}

Tables 2 - 3 show some business cycle statistics for the US economy over the period 1951:1-2004:4. The variables we have focused on are output, consumption, employment, the job finding probability, the $V U$ ratio, corporate profits and wages. All variables (except the employment rate and the $V U$ ratio) are in per capita real terms. Data on the job finding rate and vacancies come from Robert Shimer's website. Data on consumption, output, corporate profits and wages are from the Bureau of Economic Analysis (National Accounts). The employment rate is defined as 1 minus the unemployment rate as reported by the Bureau of Labor Statistics. All variables were logged and HP-filtered with a smoothing parameter of 1600 .

In terms of the volatilities, aside from the standard smaller volatilities of consumption and labor relative to output, the most noticeable feature is the high volatility of the $V U$ 
ratio with respect to GDP: it is larger by a factor of 17 . Wages are also more volatile than output but the magnitude is much smaller (a factor of 1.35). Consumption, employment, the $V-U$ ratio and wages are all quite procyclical, and employment also lags output slightly.

Tables 4-8 display the business cycle statistics for both the full insurance and the uninsurable risk economies, parameterized as described above. As is clear from Table 4, in terms of volatilities both economies are virtually indistinguishable. The volatilities of employment and consumption are almost exactly the same. There is a slight difference in the volatility of the $V-U$ ratio that increases from $86 \%$ of that of GDP in the full insurance case to $93 \%$ in the uninsurable risk economy. This is a $7 \%$ increase, negligible in light of the empirical magnitude. The volatility of real wages (last line in Table 4) is quite similar, with somewhat smoother wages in the uninsurable risk economy. The reason for this lower volatility is the one outlined before. The presence of very poor agents helps to avoid a large decrease in wages during a recession. A small drop in consumption implies a large drop in utility. This same mechanism increases wages during expansions at a smaller rate compared to the standard model. Poor individuals are satisfied with a smaller wage increase, as it raises substantially their utility level. However, as is clear from the tables in the baseline model this effect is quantitatively small. Tables 5-8 show also very small differences in the cross correlations with GDP and the persistence of macroeconomic aggregates across the two economies. The reason for the small difference is that, as it has been shown in other contexts, agents overcome quite easily the lack of perfect insurance. Although they only have one asset, physical capital, to smooth out adverse shocks, the degree of persistence of the unemployment state is not too large and agents can smooth consumption quite easily, making the two economies similar in behavior. More evidence can be obtained by looking at the wealth distribution that results from the baseline uninsurable risk economy. Figure 1 shows the cumulative distribution of capital holdings for the baseline uninsurable risk economy: the fraction of agents close to the borrowing constraint is practically zero.

In an attempt to evaluate how far the mechanism outlined in this paper can take us in 
magnifying the volatility of unemployment and vacancies we allow the discount factor to change stochastically. Instead of fixing $\beta$ at 0.99 , agents can transit across two degrees of patience: $\beta_{L}=0.1$ and $\beta_{H}=0.999$. The transition matrix that determines the conditional probabilities for these two $\beta$ s is:

$$
\Pi_{\beta}=\left[\begin{array}{ll}
0.1 & 0.9 \\
0.1 & 0.9
\end{array}\right]
$$

In the matrix $\Pi_{\beta}$ the first line shows the conditional probabilities of moving from a low patience state to a low patience and a high patience state respectively. Analogously, the second row displays the conditional probabilities of staying and moving from a high patience state. The wealth distribution for this economy is shown in Figure 2. There is a point mass of agents at the constraint, and the fraction of agents close to it is very high. The business cycle statistics for this parameterization are shown in Tables 9-11. The volatilities of the four macroeconomic aggregates that we focus on vary substantially and all the volatilities are higher than in the baseline model. For instance, employment and consumption have their standard deviations with respect to output increased by a factor of 8 and 2 respectively. The real wage is considerably smoother. The drop in its volatility represents a $19 \%$ of the volatility of the model with perfect insurance. As expected, the volatility of the $V-U$ ratio rises significantly. Its volatility relative to output is now almost 4 (3.72), which is more than four times larger than the volatility attained with the full insurance economy.

Clearly, this example is rather extreme, the fraction of agents at the borrowing constraint $(66 \%)$ is very large, the average discount factor is too low and interest rates are too high. However, quantitatively, the previous example shows that the mechanism which is the focus of this paper can have a large impact on the volatility of the $V-U$ ratio. In the remainder of this section we will explore the implications of introducing additional elements (returning to the case of a fixed discount factor) with the purpose of analyzing whether more reasonable parameterizations can be quantitatively relevant. We will focus on three features: an irreversibility constraint in investment, a minimum consumption requirement, and idiosyncratic productivity of working agents. 
The irreversibility constraint in investment hampers the ability of agents to smooth consumption by limiting the amount of capital selling an individual can undertake in the face of an adverse employment shock. Formally the constraint is written as:

$$
k^{\prime} \geq 0.99 k(1-\delta)
$$

Results for this case are displayed on Tables 12-14. The quantitative impact of the irreversibility constraint is small. The only statistic that changes somewhat is the variability of the $V-U$ ratio, which increases to a value of 1.05 (relative to output). The cross correlations with output and the persistence of the macroeconomic series is quantitatively very similar to the baseline idiosyncratic risk economy. The only minor difference is that consumption is somewhat more persistent and a bit more procyclical. The second feature we introduced was a minimum consumption requirement so that now the per-period utility function becomes $u(c-\underline{c})$. For this experiment we removed the irreversibility constraint on investment. We experimented with three different values for $\underline{c}$ : $0.01,0.1$ and 0.2. Tables $15-17$ display results for $\underline{c}=0.1^{2}$. This new parameterization adds quantitatively very little when compared with the baseline uninsured individual risk. The two economies are virtually indistinguishable. Finally, we increased the volatility of earnings by adding uncertain productivity levels for agents working. We denote this productivity shock by $\epsilon$. This transforms the budget constraint for the worker to:

$$
c^{e}+k^{e^{\prime}}=w \epsilon+R k+(1-\delta) k
$$

The shock can take on two values: $\epsilon_{L}=0.1$ and $\epsilon_{H}=9.1$. The transition matrix with the probabilities of moving or staying in a given productivity level (conditional on remaining employed) is:

$$
\Pi_{\epsilon}=\left[\begin{array}{ll}
0.1 & 0.9 \\
0.1 & 0.9
\end{array}\right]
$$

We show in Tables 18-20 the business cycle statistics for this economy. There is improvement with respect to the previous two modifications, but the standard deviation

\footnotetext{
${ }^{2}$ Results with $\underline{c}$ equal to 0.01 and 0.2 were very similar.
} 
of the $V-U$ ratio is still far from its empirical value. Its volatility with respect to output is now 2, which is a bit more than twice that of the full insurance case. The real wage is somewhat smoother, 0.82 relative to output, while in the full insurance and the baseline uninsured risk economies, the volatility of real wages was well above 0.90. The asset CDFs for this and the baseline uninsurable risk economies are shown in Figure 3. In the idiosyncratic productivity economy the wealth inequality is significantly larger, with a smaller fraction of agents holding "average levels of capital". In addition, the fraction of agents closer to the borrowing constraint is also larger, contributing to the doubling of the volatility of the $V-U$ ratio in comparison to the baseline economy.

\section{Conclusion}

The attitude towards risk and the absence of perfect insurance is an assumption that is missing from many studies of economic fluctuations with search in the labor markets. Our research shows that the heterogeneity in asset holdings that results from assuming that agents cannot insure perfectly the idiosyncratic risk acts as a mechanism that decreases the volatility of wages and increases the volatility of the $V-U$ ratio. The reason is that when negotiating wages, the fraction of poor workers accept lower wages than they otherwise would. Our starting point has been the Mortensen-Pissarides economy, to which we have added idiosyncratic risk and limited the ability of agents to insure against that risk. We show how heterogeneity in asset holdings helps when bringing the model's implication closer to the data. However, for this channel to have a large quantitative effect a large fraction of agents needs to be close to or at the borrowing constraint.

In most parameterizations, although agents only have access to one asset to smooth consumption, the degree of self insurance is remarkably good. The Mortensen-Pissarides economy where agents are unable to perfectly insure against the risk of being separated from their current job or not being matched with a firm, is virtually indistinguishable

from the complete markets economy. To obtain sizable differences in the volatility of the $V-U$ ratio one needs to obtain high wealth inequality. Two features that we have explored here are, first, to assume that agents have varying degrees of patience, which 
affect the preferred rate of asset accumulation; and second, to assume a large dispersion in productivity within working agents. Each of these two features increases substantially the standard deviation of the $V-U$ ratio relative to output. However, only in the heterogeneous patience case is the change large enough to have a considerable impact on the volatility as compared to its empirical value. We conclude that other omissions from the model must be chiefly responsible of the low volatility of the $V-U$ ratio. 


\section{A Solution Algorithm}

The relevant aggregate state variables in the individual's problem is $\tilde{\chi}=(z, N, K)$. Notice that we have already replaced the distribution $Q$ by its first moment $K$. As we show below, the accuracy of projecting $K^{\prime}, w$ and $\pi$ on just $K$ and $N$ is extremely good. The solution of the model entails computing the following objects.

1. Optimal decision rules for consumption $c^{e}(k ; \tilde{\chi})$ and $c^{u}(k ; \tilde{\chi})$, the value function $J(k ; \tilde{\chi})$ and the marginal value of employment $(\partial J / \partial N)(k ; \tilde{\chi})$,

2. a matching probability function $\pi(\tilde{\chi})$,

3. a wage function $w(\tilde{\chi})$

4. the law of motion for aggregate capital $K^{\prime}(\tilde{\chi})$.

\section{A.1 Overview of the Algorithm}

The solution algorithm is made up of the following steps (we will fill in the details in later subsection):

1. Choose aggregate grid points for $N$ and $K$ and the individual asset grid $k$.

2. Choose the class of polynomials to approximate the aggregate law of motion $K^{\prime}(\tilde{\chi})$, the job finding rate $\pi(\tilde{\chi})$ and the wage function $w(\tilde{\chi})$. Make an initial guess on the coefficients of above functions. Choose suitable interpolation schemes to approximate the consumption functions $c^{e}(k ; \chi)$ and $c^{u}(k ; \tilde{\chi})$, the decision rules $k_{e}^{\prime}(k ; \tilde{\chi})$ and $k_{u}^{\prime}(k ; \tilde{\chi})$, and the value functions $J(k ; \tilde{\chi})$ and $(\partial J / \partial N)(k ; \tilde{\chi})$.

3. For a given aggregate law of motion, job finding probability and wage rate, solve for the workers problem. This step involves solving for $c^{e}, c^{u}, k_{e}^{\prime}, k_{u}^{\prime}, J$ and $\partial J / \partial N$ at each grid point.

4. Given an initial guess on the wealth distribution, simulate the economy for a long time series and use the policy rules obtained in (3) to calculate the wealth distri- 
bution $Q$, the matching probability $\pi$ and the wage rate for each period. This step involves iteratively solving for the optimal job posting equation (15).

5. Use the stationary region of the simulated data to estimate the new coefficients in $K^{\prime}(\tilde{\chi}), \pi(\tilde{\chi})$, and $w(\tilde{\chi})$.

6. Repeat steps 3-5 until convergence of the relevant functions is achieved.

7. Check whether the goodness of fit is satisfactory. It it is not, then increase the moments used to approximate the wealth distribution or try a different functional forms for $K^{\prime}, \pi$ and $w$.

\section{A.2 Detail Description of the Algorithm}

\section{A.2.1 Solving the worker's optimization problem}

1. Setup the grid on $k^{\prime}$, the end of period capital holdings (or next period capital holdings). The grid of points is $\left\{k_{1}^{\prime}, \ldots, k_{n}^{\prime}\right\}$ with $k_{1}^{\prime}=\underline{k}$ the borrowing limit. Usually this grid is finer than the asset grid $k$.

2. Initially assume that workers do not save for tomorrow, which means they will consume all the income:

$$
\begin{aligned}
c_{0}^{e} & =(R(\tilde{\chi})+1-\delta) k+w(\tilde{\chi}), \\
c_{0}^{u} & =(R(\tilde{\chi})+1-\delta) k .
\end{aligned}
$$

Then calculate the value functions

$$
\begin{aligned}
J_{0} & =N u\left(c_{0}^{e}\right)+(1-N) u\left(c_{0}^{u}\right), \\
\left(\frac{\partial J}{\partial N}\right)_{0} & =u\left(c_{0}^{e}\right)-u\left(c_{0}^{u}\right) .
\end{aligned}
$$

3. At iteration step $t \geq 1$, given any approximation of policy functions $c_{t-1}^{e}$ and $c_{t-1}^{u}$, 
calculate next period marginal utilities of consumption at each grid point $\left(k_{i}^{\prime}, \tilde{\chi}\right)$ :

$$
\begin{aligned}
M U^{e}\left(k_{i}^{\prime}, \tilde{\chi}\right)= & \sum_{z^{\prime}} p\left(z^{\prime} \mid z\right) R\left(\tilde{\chi}^{\prime}\right) \times \\
& N^{\prime}(\tilde{\chi}) u^{\prime}\left(c_{t-1}^{e}\left(k_{i}^{\prime}, \tilde{\chi}^{\prime}\right)\right), \\
M U^{u}\left(k_{i}^{\prime}, \tilde{\chi}\right)= & \sum_{z^{\prime}} p\left(z^{\prime} \mid z\right) R\left(\tilde{\chi}^{\prime}\right) \times \\
& \left(1-N^{\prime}(\tilde{\chi})\right) u^{\prime}\left(c_{t-1}^{u}\left(k_{i}^{\prime}, \tilde{\chi}^{\prime}\right)\right),
\end{aligned}
$$

where $N^{\prime}(\tilde{\chi})=(1-s) N+\pi(\tilde{\chi}) N$.

4. From the Euler equations

$$
u^{\prime}\left(\tilde{c}^{j}\right)=\beta\left(M U^{e}\left(k_{i}^{\prime}, \tilde{\chi}\right)+M U^{u}\left(k_{i}^{\prime}, \tilde{\chi}\right)\right)
$$

we can calculate the current consumption $\left(\widetilde{c}_{i}^{e}, \widetilde{c}_{i}^{u}\right)$ for each grid points $k_{i}^{\prime}, i=1, \ldots, n$. Since equation (??) is the same for employed or unemployed, we can suppress the superscript on $\widetilde{c}$.

5. Use the budget constraints to recover the market resources (or income) at the beginning of current period

$$
\widetilde{y}_{i}=\widetilde{c}_{i}+k_{i}^{\prime}
$$

6. Then $\left\{\widetilde{y}_{i}\right\}_{i=1}^{n}$ forms an endogenous grid on current income. Based on the set of pairs $\left\{\left(\widetilde{y}_{i}, \widetilde{c}_{i}\right)\right\}_{i=1}^{n}$, because

$$
\begin{aligned}
y^{e} & =(R(\tilde{\chi})+1-\delta) k+w(\tilde{\chi}), \\
y^{u} & =(R(\tilde{\chi})+1-\delta) k,
\end{aligned}
$$

we can simply use linear interpolation or other shape preserving schemes to obtain the policy functions $\hat{c}^{j}\left(y^{j}, \tilde{\chi}\right)$ for given values of aggregate states $(\tilde{\chi})$. We can update the optimal consumption $c_{t}^{j}(k, \tilde{\chi})$ from $\hat{c}^{j}\left(y^{j}, \tilde{\chi}\right){ }^{3}$

\footnotetext{
${ }^{3}$ To handle the borrowing constraints $k_{j}^{\prime} \geq \underline{k}, j=e, u$, we need to do the following. If for any given values of $(k, \tilde{\chi}), y^{j} \leq \widetilde{y}_{1}$, it implies that the borrowing constraint binds, we set $c_{t}^{j}(k, \tilde{\chi})=y^{j}-\underline{k}$ and $k_{j}^{\prime}(k, \tilde{\chi})=\underline{k}$.
} 
7. Given those values computed in (6), we then interpolate $c_{t}^{e}$ and $c_{t}^{u}$ among aggregate states $(z, N, m)$.

8. Once we have the optimal comsumptions $\left(c_{t}^{e}, c_{t}^{u}\right)$ and the value function $J_{t-1}$, we compute the new value function

$$
\begin{aligned}
& J_{t}(k, z, N, m)=N\left[\begin{array}{c}
u\left(c_{t}^{e}(k, \tilde{\chi})\right) \\
+\beta \sum_{z^{\prime}} p\left(z^{\prime} \mid z\right) J_{t-1}\left(k_{e}^{\prime}, \tilde{\chi}^{\prime}\right)
\end{array}\right] \\
& +(1-N)\left[\begin{array}{c}
u\left(c_{t}^{u}(k, \tilde{\chi})\right) \\
+\beta \sum_{z^{\prime}} p\left(z^{\prime} \mid z\right) J_{t-1}\left(k_{u}^{\prime}, \tilde{\chi}^{\prime}\right)
\end{array}\right],
\end{aligned}
$$

where $k_{j}^{\prime}$ can be calculated from

$$
\begin{aligned}
k_{e}^{\prime}(k, \tilde{\chi}) & =(R(\tilde{\chi})+1-\delta) k+w(\tilde{\chi})-c_{t}^{e}(k, \tilde{\chi}) \\
k_{u}^{\prime}(k, \tilde{\chi}) & =(R(\tilde{\chi})+1-\delta) k-c_{t}^{u}(k, \tilde{\chi})
\end{aligned}
$$

9. Use $\left(c_{t}^{e}, c_{t}^{u}, J_{t}\right)$ and $(\partial J / \partial N)_{t-1}$ to update the new marginal value of employment:

$$
\begin{array}{r}
\left(\frac{\partial J}{\partial N}\right)_{t}(k, z, N, m)=u\left(c_{t}^{e}\right)-u\left(c_{t}^{u}\right)+\beta \sum_{z^{\prime}} p\left(z^{\prime} \mid z\right)\left(\begin{array}{c}
J\left(k_{e}^{\prime}, \tilde{\chi}^{\prime}\right) \\
-J\left(k_{u}^{\prime}, \tilde{\chi}^{\prime}\right)
\end{array}\right) \\
+(1-s-\pi(\tilde{\chi}))\left[\begin{array}{c}
N \beta \sum_{z^{\prime}} p\left(z^{\prime} \mid z\right)\left(\frac{\partial J}{\partial N}\right)_{t-1}\left(k_{e}^{\prime}, \tilde{\chi}^{\prime}\right) \\
+(1-N) \beta \sum_{z^{\prime}} p\left(z^{\prime} \mid z\right)\left(\frac{\partial J}{\partial N}\right)_{t-1}\left(k_{u}^{\prime}, \tilde{\chi}^{\prime}\right)
\end{array}\right] .
\end{array}
$$

10. Repeat steps (3)-(9) until $c^{e}, c^{u}, J, \partial J / \partial N$ converge.

Since we solve the model on a discrete grid of points, the policy functions and value functions that we describe in the above steps have to be approximated between grid points. A good interpolation method that preserves the monotonicity and concavity of the value function is crucial for the stability and accuracy of the algorithm. Most Chebychev polynomial basis interpolation or other higher order approximations, including many forms of splines, can destroy the stability of the algorithm by producing internodal oscillations. For the sake of stability, we use the simplicial linear interpolation described in Judd (1998) which preserves the contraction property of the Bellman operator, which guarantees convergence. Since the dimension is less than 4 , the simplicial linear interpolation is relatively easy to implement in our application. We setup the grid in $k$ and $k^{\prime}$ direction so that we include many points near the borrowing limits (where there is a lot of curvature) and few 
grid points for larger values. The number of points are 50-60 for $k$ and 150-200 for $k^{\prime}$. Our results are not sensitive to increasing the number of grid points in either the $k$ or $k^{\prime}$ direction.

\section{A.2.2 Computation of the wealth distribution}

One of main steps in solving the model is to pin down the law of motion $K^{\prime}$. In order to calculate it, we need to derive a time series of aggregate capital stocks $\left\{K_{t}\right\}_{t=1}^{T}$ and use this time series to estimate the transition function $H$ mapping $K_{t+1}$ into $K_{t}$. One possible approach to generate $K_{t}$ is to simulate the behavior of a large number of consumers for each time period as proposed in Krusell and Smith (1998) and compute $K_{t}$ as the average of their holdings. The drawback of this simulation method is that it is inaccurate, even with a very large number of agents. Here we discretize the state space and approximate the CDF as a step function to avoid doing any Monte Carlo simulation. The computation can be summarized as follows:

1. Simulate a long time series of aggregate shocks of length $T$ using the transition matrix (23).

2. Specify grids on individual capital holdings $k$ such that the grid is finer than the one used to compute the optimal decision rules. We use 240 to 400 grid points in this step.

3. Choose an initial distribution function $Q_{0}(k)$ over the grid. We generally assume that everyone has the same capital stock to begin with. We also try other distribution function such as uniform distribution, but it won't affect the result.

4. Use the decision rules calculated from section A.2.1, we can compute the inverse of the decision rules $k_{i}^{j}=k_{j}^{\prime-1}\left(k_{i}, \tilde{\chi}\right), j=e, u$, over the chosen grid.

5. Given the distribution $Q_{n}$ and aggregate values $(\tilde{\chi})$ at time period $n$, the distribution at $n+1$ is

$$
Q_{n+1}\left(k_{i}\right)=N Q_{n}\left(k_{e}^{\prime-1}\left(k_{i}, \tilde{\chi}\right)\right)+(1-N) Q_{n}\left(k_{u}^{\prime-1}\left(k_{i}, \tilde{\chi}\right)\right)
$$


on grid points $k_{i}$. For those points $k_{i}^{j}=k_{j}^{\prime-1}\left(k_{i}, \tilde{\chi}\right)$ are not grid points, we use linear interpolation to calculate $Q_{n}\left(k_{i}^{j}\right)$.

6. Compute the aggregate moments at time $n+1$ using $Q_{n+1}$. For example the aggregate capital is given by

$$
K_{n+1}=k_{1} Q_{n+1}\left(k_{1}\right)+\sum_{i=2}^{\eta_{k}}\left(Q_{n+1}\left(k_{i}\right)-Q_{n+1}\left(k_{i-1}\right)\right)\left(k_{i}+k_{i-1}\right) / 2 .
$$

where $\eta_{k}$ is the number of grid points in $k$ for the purpose of computing the wealth distribution. The dimension of this grid should be in general larger than the dimension of the grid to compute the decision rules.

7. After getting the long time series for aggregate capital, we can run the regressions to compute the law of motion for $K^{\prime}$ and the $\pi$ and $w$ functions.

\section{A.2.3 Solving the optimal job posting}

To find the wage and the matching probability, it is necessary to solve for the optimal vacancies in equation (15). Notice that (15) is a nonlinear in $V$, which appears in both hand sides of the equation. ${ }^{4}$ We may use nonlinear equation solver to solve for $V$, however, it is easy to fail in getting the solution. We use similar idea of solving the worker's problem to iteratively find the fixed point of $V$.

Along the simulation path, for any period of time $n$, we are given the value of aggregate states $(\tilde{\chi})$. (1) We start with an initial guess on $V$, then we calculate the next period employment $N^{\prime}$ and the left-hand side of equation (15). (2) Use the procedure in section A.2.2 to compute the next period wealth distribution and update the aggregate moments for the next period. (3) Base on states $\left(\tilde{\chi}^{\prime}\right)$ and distribution $Q^{\prime}$, calculate the righ-hand side of equation (15) using the functions from section (A.2.1). (4) If the difference between both hand side of the equation is smaller than the tolerance value, stop; otherwise repeat steps $(1)-(3)$.

\footnotetext{
${ }^{4}$ The left-hand side can be written as $\frac{\omega}{\mu}\left(\frac{V}{1-N}\right)^{1-\gamma}$. On the right-hand side, the function $\partial J\left(k^{\prime}, \tilde{\chi}^{\prime}\right) / \partial N^{\prime}$ is a function of $N^{\prime}$ which in turn implicitly depends on $V$.
} 
As one can see, the above iterative procedure is embedded into the computation of the wealth distribution. Once we solve for $V$, we can calculate $w$ and $\pi$ for any particular time period.

\section{A.3 Numerical Solution}

Table 21 documents some details about the numerical solutions. In choosing the grid points for individual capital, the borrowing constraint provides the lower bound for $k$. The upper bound of $k$ is set to be $3-4$ times larger than the steady state value of aggregate capital in the full insurance case. Unfortunately, there is no much guidance available when specifying the grids for the aggregate states. Finding sensible bounds required substantial trial and error. We chose a log-linear form for the law of motion of $K^{\prime}$ and for $w$ and $\pi$. The coefficients in these functions are obtained by running OLS regressions. We report the equilibrium results in Tables 22-23. We can see that the measures of fit, either the $R^{2}$ or the relative errors, are extremely good, showing that increasing the moments in the wealth distribution would bring marginal gains. 


\section{References}

[1] Acemoglu, D. and Shimer, R., (1999), "Efficient Unemployment Insurance", Journal of Political Economy, Vol. 107, No. 5, pp. 893-928.

[2] Andolfatto, D., (1996), "Business Cycles and Labor-Market Search", American Economic Review, Vol. 96, No. 1, pp. 112-132.

[3] Judd, K. L., (1998), Numerical Methods in Economics, MIT Press, Cambridge, MA.

[4] Krusell, P. and Smith, A.A., (1998), "Income and Wealth Heterogeneity and the Macroeconomy", Journal of Political Economy, Vol. 106, No. 5, pp. 867-896.

[5] Merz, M., (1995), "Search in the Labor Market and the Real Business Cycle", Journal of Monetary Economics, Vol. 36, pp. 269-300.

[6] Mortensen, D. and Pissarides, C., (1994), "Job Creation and Job Destruction in the Theory of Unemployment", Review of Economics Studies 61(3), pp. 397-415.

[7] Pissarides, C. (2001), Equilibrium Unemployment Theory, MIT Press, Cambridge, MA, 2nd edn.

[8] Rudanko, L., (2006), "Labor Market Dynamics under Long Term Wage Contracting and Incomplete Markets", manuscript, University of Chicago.

[9] Shimer, R., (2005), "The Cyclical Behavior of Unemployment and Vacancies", American Economic Review, Vol. 95, No. 1, pp. 25-49. 
Table 2: Standard Deviations (US Data)

\begin{tabular}{cc}
$\mathrm{N}$ & 0.49 \\
$\mathrm{C}$ & 0.53 \\
$\mathrm{~V}-\mathrm{U}$ & 16.58 \\
$\pi$ & 6.85 \\
Wage Rate & 0.68 \\
\hline
\end{tabular}

Table 3: Cross-Correlations of $x$ with Output (US Data)

\begin{tabular}{cccccccc} 
Variable & $x_{t-3}$ & $x_{t-2}$ & $x_{t-1}$ & $x_{t}$ & $x_{t+1}$ & $x_{t+2}$ & $x_{t+3}$ \\
\hline \hline
\end{tabular}

\begin{tabular}{cccccccc}
$\mathrm{N}$ & 0.23 & 0.46 & 0.69 & 0.83 & 0.86 & 0.74 & 0.55 \\
$\mathrm{C}$ & 0.31 & 0.54 & 0.72 & 0.85 & 0.76 & 0.62 & 0.44 \\
$\mathrm{~V}-\mathrm{U}$ & 0.27 & 0.51 & 0.72 & 0.84 & 0.83 & 0.69 & 0.50 \\
Wage & 0.71 & 0.70 & 0.65 & 0.53 & 0.37 & 0.19 & 0.02 \\
\hline
\end{tabular}

Table 4: Standard Deviations (Relative to Output) Variable Full Insurance Uninsured Risk

\begin{tabular}{ccc}
\hline \hline & & \\
$\mathrm{N}$ & 0.03 & 0.03 \\
$\mathrm{C}$ & 0.27 & 0.26 \\
$\mathrm{~V}-\mathrm{U}$ & 0.86 & 0.93 \\
Wage & 0.95 & 0.92 \\
\hline
\end{tabular}

Table 5: Cross-Correlations of $x$ with Output (Uninsured Risk)

\begin{tabular}{cccccccc} 
Variable & $x_{t-3}$ & $x_{t-2}$ & $x_{t-1}$ & $x_{t}$ & $x_{t+1}$ & $x_{t+2}$ & $x_{t+3}$ \\
\hline \hline $\mathrm{N}$ & 0.03 & 0.20 & 0.40 & 0.66 & 0.98 & 0.82 & 0.56 \\
$\mathrm{C}$ & 0.00 & 0.22 & 0.51 & 0.88 & 0.75 & 0.62 & 0.49 \\
$\mathrm{~V}-\mathrm{U}$ & 0.23 & 0.44 & 0.69 & 1.00 & 0.68 & 0.43 & 0.23 \\
Wage & 0.23 & 0.44 & 0.69 & 1.00 & 0.68 & 0.42 & 0.22 \\
\hline
\end{tabular}

Table 6: Cross-Correlations of $x$ with Output (Full Insurance)

\begin{tabular}{cccccccc} 
Variable & $x_{t-3}$ & $x_{t-2}$ & $x_{t-1}$ & $x_{t}$ & $x_{t+1}$ & $x_{t+2}$ & $x_{t+3}$ \\
\hline \hline $\mathrm{N}$ & 0.01 & 0.17 & 0.38 & 0.64 & 0.96 & 0.83 & 0.59 \\
$\mathrm{C}$ & 0.03 & 0.26 & 0.55 & 0.92 & 0.75 & 0.60 & 0.45 \\
$\mathrm{~V}-\mathrm{U}$ & 0.21 & 0.42 & 0.68 & 0.99 & 0.75 & 0.51 & 0.29 \\
Wage & 0.23 & 0.43 & 0.69 & 1.00 & 0.69 & 0.43 & 0.23 \\
\hline
\end{tabular}


Table 7: Autocorrelations (Uninsured Risk)

\begin{tabular}{cccc} 
Variable & 1st Lag & 2nd Lag & 3rd Lag \\
\hline \hline & & & \\
Y & 0.69 & 0.44 & 0.23 \\
N & 0.80 & 0.52 & 0.28 \\
$\mathrm{C}$ & 0.79 & 0.59 & 0.41 \\
V-U & 0.68 & 0.43 & 0.23 \\
Wage & 0.68 & 0.42 & 0.22 \\
\hline
\end{tabular}

Table 8: Autocorrelations (Full Insurance) Variable 1st Lag 2nd Lag 3rd Lag

\begin{tabular}{cccc}
\hline \hline & & & \\
$\mathrm{Y}$ & 0.69 & 0.44 & 0.23 \\
$\mathrm{~N}$ & 0.80 & 0.42 & 0.21 \\
$\mathrm{C}$ & 0.76 & 0.55 & 0.36 \\
$\mathrm{~V}-\mathrm{U}$ & 0.75 & 0.49 & 0.27 \\
Wage & 0.70 & 0.44 & 0.24 \\
\hline
\end{tabular}

Table 9: Standard Deviations (Relative to Output)

\begin{tabular}{cc} 
Variable & Heterogeneous Patience \\
\hline \hline & \\
$\mathrm{N}$ & 0.25 \\
$\mathrm{C}$ & 0.69 \\
$\mathrm{~V}-\mathrm{U}$ & 3.72 \\
Wage & 0.77 \\
\hline
\end{tabular}

Table 10: Cross-Correlations of $x$ with Output (Heterogeneous Patience)

\begin{tabular}{cccccccc} 
Variable & $x_{t-3}$ & $x_{t-2}$ & $x_{t-1}$ & $x_{t}$ & $x_{t+1}$ & $x_{t+2}$ & $x_{t+3}$ \\
\hline \hline & & & & & & & \\
$\mathrm{N}$ & 0.13 & 0.35 & 0.58 & 0.81 & 0.96 & 0.95 & 0.85 \\
$\mathrm{C}$ & 0.49 & 0.71 & 0.91 & 1.00 & 0.89 & 0.68 & 0.44 \\
$\mathrm{~V}-\mathrm{U}$ & 0.61 & 0.80 & 0.93 & 0.90 & 0.63 & 0.37 & 0.15 \\
Wage & 0.58 & 0.78 & 0.94 & 0.96 & 0.74 & 0.49 & 0.25 \\
\hline
\end{tabular}

Table 11: Autocorrelations (Heterogeneous Patience)

\begin{tabular}{cccc} 
Variable & 1st Lag & 2nd Lag & 3rd Lag \\
\hline \hline & & & \\
$\mathrm{Y}$ & 0.90 & 0.70 & 0.47 \\
$\mathrm{~N}$ & 0.93 & 0.78 & 0.59 \\
$\mathrm{C}$ & 0.90 & 0.69 & 0.46 \\
$\mathrm{~V}-\mathrm{U}$ & 0.77 & 0.53 & 0.31 \\
Wage & 0.84 & 0.60 & 0.37 \\
\hline
\end{tabular}


Table 12: Standard Deviations (Relative to Output)

\begin{tabular}{cc} 
Variable & Irreversible Investment \\
\hline \hline & \\
$\mathrm{N}$ & 0.04 \\
$\mathrm{C}$ & 0.39 \\
$\mathrm{~V}-\mathrm{U}$ & 1.02 \\
Wage & 0.95 \\
\hline
\end{tabular}

Table 13: Cross-Correlations of $x$ with Output (Irreversible Investment)

\begin{tabular}{cccccccc} 
Variable & $x_{t-3}$ & $x_{t-2}$ & $x_{t-1}$ & $x_{t}$ & $x_{t+1}$ & $x_{t+2}$ & $x_{t+3}$ \\
\hline \hline & & & & & & & \\
$\mathrm{N}$ & 0.04 & 0.20 & 0.41 & 0.67 & 0.98 & 0.81 & 0.55 \\
$\mathrm{C}$ & 0.13 & 0.35 & 0.63 & 0.98 & 0.73 & 0.52 & 0.34 \\
$\mathrm{~V}-\mathrm{U}$ & 0.23 & 0.44 & 0.69 & 1.00 & 0.67 & 0.42 & 0.21 \\
Wage & 0.23 & 0.44 & 0.69 & 1.00 & 0.67 & 0.42 & 0.22 \\
\hline
\end{tabular}

Table 14: Autocorrelations (Irreversible Investment)

\begin{tabular}{cccc} 
Variable & 1st Lag & 2nd Lag & 3rd Lag \\
\hline \hline & & & \\
$\mathrm{Y}$ & 0.69 & 0.43 & 0.23 \\
$\mathrm{~N}$ & 0.80 & 0.52 & 0.27 \\
$\mathrm{C}$ & 0.71 & 0.47 & 0.27 \\
V-U & 0.68 & 0.42 & 0.22 \\
Wage & 0.68 & 0.43 & 0.22 \\
\hline
\end{tabular}

Table 15: Standard Deviations (Relative to Output)

\begin{tabular}{cc} 
Variable & Minimum Consumption \\
\hline \hline & \\
$\mathrm{N}$ & 0.03 \\
$\mathrm{C}$ & 0.26 \\
V-U & 0.93 \\
Wage & 0.92 \\
\hline
\end{tabular}

Table 16: Cross-Correlations of $x$ with Output (Minimum Consumption)

\begin{tabular}{cccccccc} 
Variable & $x_{t-3}$ & $x_{t-2}$ & $x_{t-1}$ & $x_{t}$ & $x_{t+1}$ & $x_{t+2}$ & $x_{t+3}$ \\
\hline \hline $\mathrm{N}$ & 0.02 & 0.18 & 0.38 & 0.64 & 0.95 & 0.83 & 0.58 \\
$\mathrm{C}$ & 0.00 & 0.22 & 0.51 & 0.89 & 0.75 & 0.61 & 0.48 \\
$\mathrm{~V}-\mathrm{U}$ & 0.21 & 0.42 & 0.68 & 0.99 & 0.75 & 0.51 & 0.29 \\
Wage & 0.22 & 0.43 & 0.69 & 1.00 & 0.74 & 0.48 & 0.26 \\
\hline
\end{tabular}


Table 17: Autocorrelations (Minimum Consumption)

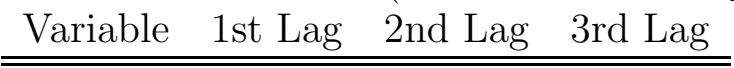

\begin{tabular}{cccc}
\hline \hline & & & \\
$\mathrm{Y}$ & 0.69 & 0.43 & 0.23 \\
$\mathrm{~N}$ & 0.77 & 0.49 & 0.26 \\
$\mathrm{C}$ & 0.77 & 0.57 & 0.38 \\
$\mathrm{~V}-\mathrm{U}$ & 0.65 & 0.41 & 0.23 \\
Wage & 0.73 & 0.47 & 0.25 \\
\hline
\end{tabular}


Table 18: Standard Deviations (Relative to Output)

Variable High Earnings Variability

\begin{tabular}{cc}
\hline \hline & \\
$\mathrm{N}$ & 0.07 \\
$\mathrm{C}$ & 0.15 \\
$\mathrm{~V}-\mathrm{U}$ & 1.98 \\
Wage & 0.82 \\
\hline
\end{tabular}

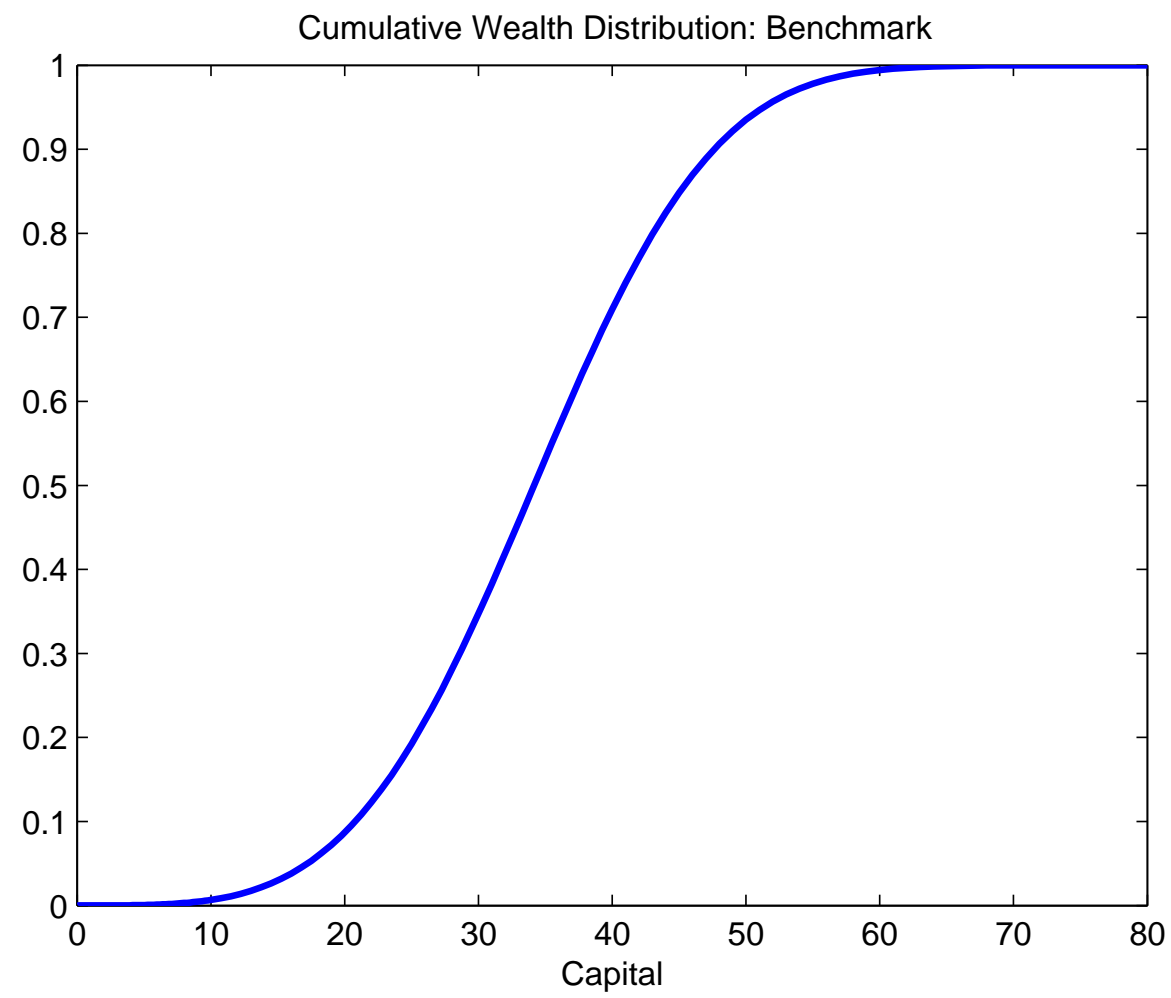

Figure 1: CDF of asset holdings in the baseline uninsurable risk economy. 
Table 19: Cross-Correlations of $x$ with Output (High Earnings Variability)

\begin{tabular}{cccccccc} 
Variable & $x_{t-3}$ & $x_{t-2}$ & $x_{t-1}$ & $x_{t}$ & $x_{t+1}$ & $x_{t+2}$ & $x_{t+3}$ \\
\hline \hline $\mathrm{N}$ & 0.07 & 0.23 & 0.44 & 0.70 & 0.99 & 0.79 & 0.52 \\
$\mathrm{C}$ & 0.04 & 0.26 & 0.55 & 0.90 & 0.78 & 0.65 & 0.51 \\
$\mathrm{~V}-\mathrm{U}$ & 0.26 & 0.47 & 0.71 & 1.00 & 0.75 & 0.51 & 0.29 \\
Wage & 0.24 & 0.45 & 0.70 & 1.00 & 0.67 & 0.42 & 0.22 \\
\hline
\end{tabular}

Table 20: Autocorrelations (High Earnings Variability)

\begin{tabular}{cccc} 
Variable & 1st Lag & 2nd Lag & 3rd Lag \\
\hline \hline & & & \\
$\mathrm{Y}$ & 0.70 & 0.45 & 0.24 \\
$\mathrm{~N}$ & 0.78 & 0.51 & 0.27 \\
$\mathrm{C}$ & 0.80 & 0.61 & 0.42 \\
V-U & 0.67 & 0.41 & 0.20 \\
Wage & 0.67 & 0.42 & 0.22 \\
\hline
\end{tabular}

Table 21: Details of numerical solutions

Property Benchmark $\quad$ Full Irreversible

\begin{tabular}{cccc} 
& & Insurance & Investment \\
\hline \hline Moments Used & Mean & Mean & Mean \\
Interpolation Method & Piecewise Linear & Piecewise Linear & Piecewise Linear \\
Grid Dimension & & & \\
Individual Problem & $\eta_{k}=50, \eta_{k^{\prime}}=150$ & $\mathrm{~N} / \mathrm{A}$ & $\eta_{k}=55, \eta_{k^{\prime}}=200$ \\
Aggregate States & $\eta_{N}=5, \eta_{K}=5$ & $\eta_{N}=10, \eta_{K}=50$ & $\eta_{N}=5, \eta_{K}=5$ \\
Wealth Distribution & $\eta_{k}=240$ & $\mathrm{~N} / \mathrm{A}$ & $\eta_{k}=350$ \\
Functional Form & $\log$ Linear & Log Linear & Log Linear
\end{tabular}

Table 22: Equilibrium Results of Benchmark Model

\begin{tabular}{llll} 
Function & Coefficients & $R^{2}$ & Relative Errors \\
\hline \hline$H_{I}$ & $\ln K^{\prime}=0.117+0.073 \ln z+0.131 \ln N+0.972 \ln K$ & 1.0 & $0.01 \%$ \\
$w(z h)$ & $\ln w=-0.220+1.033 \ln N+0.341 \ln K$ & 1.0 & $0.02 \%$ \\
$w(z l)$ & $\ln w=-0.234+1.055 \ln N+0.340 \ln K$ & 1.0 & $0.02 \%$ \\
$\pi(z h)$ & $\ln \pi=-0.612+1.145 \ln N+0.087 \ln K$ & 1.0 & $0.02 \%$ \\
$\pi(z l)$ & $\ln \pi=-0.612+1.160 \ln N+0.087 \ln K$ & 1.0 & $0.02 \%$
\end{tabular}

Table 23: Equilibrium Results of Irreversible Investment

\begin{tabular}{llll} 
Function & Coefficients & $R^{2}$ & Relative Errors \\
\hline \hline$H_{I}$ & $\ln K^{\prime}=0.099+0.037 \ln z+0.065 \ln N+0.980 \ln K$ & 1.0 & $0.01 \%$ \\
$w(z h)$ & $\ln w=-0.287+0.658 \ln N+0.351 \ln K$ & 1.0 & $0.05 \%$ \\
$w(z l)$ & $\ln w=-0.302+0.663 \ln N+0.350 \ln K$ & 1.0 & $0.05 \%$ \\
$\pi(z h)$ & $\ln \pi=-0.663+1.029 \ln N+0.078 \ln K$ & 1.0 & $0.02 \%$ \\
$\pi(z l)$ & $\ln \pi=-0.674+1.026 \ln N+0.079 \ln K$ & 1.0 & $0.02 \%$
\end{tabular}




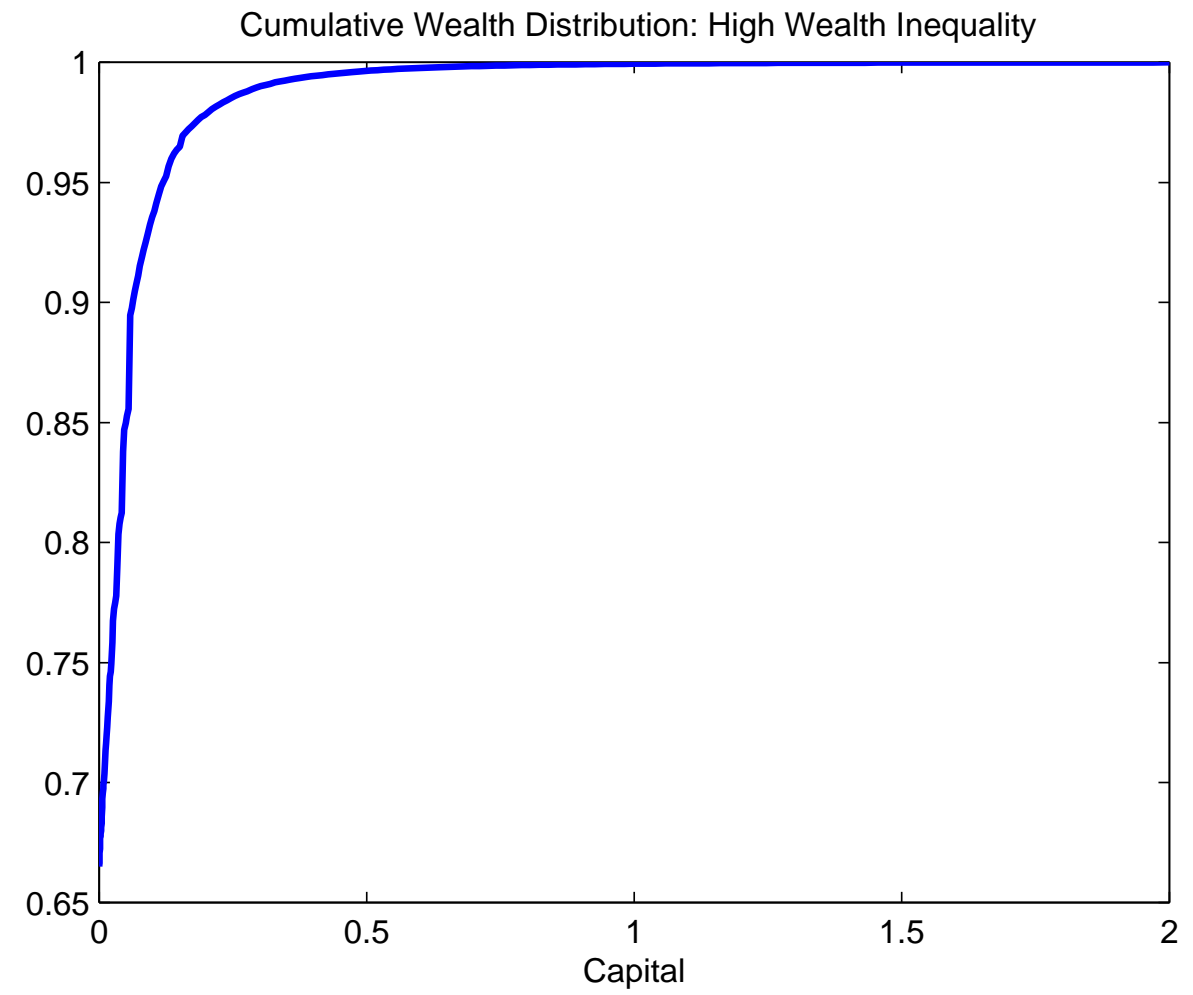

Figure 2: CDF of asset holdings in the economy with varying discount factors. 


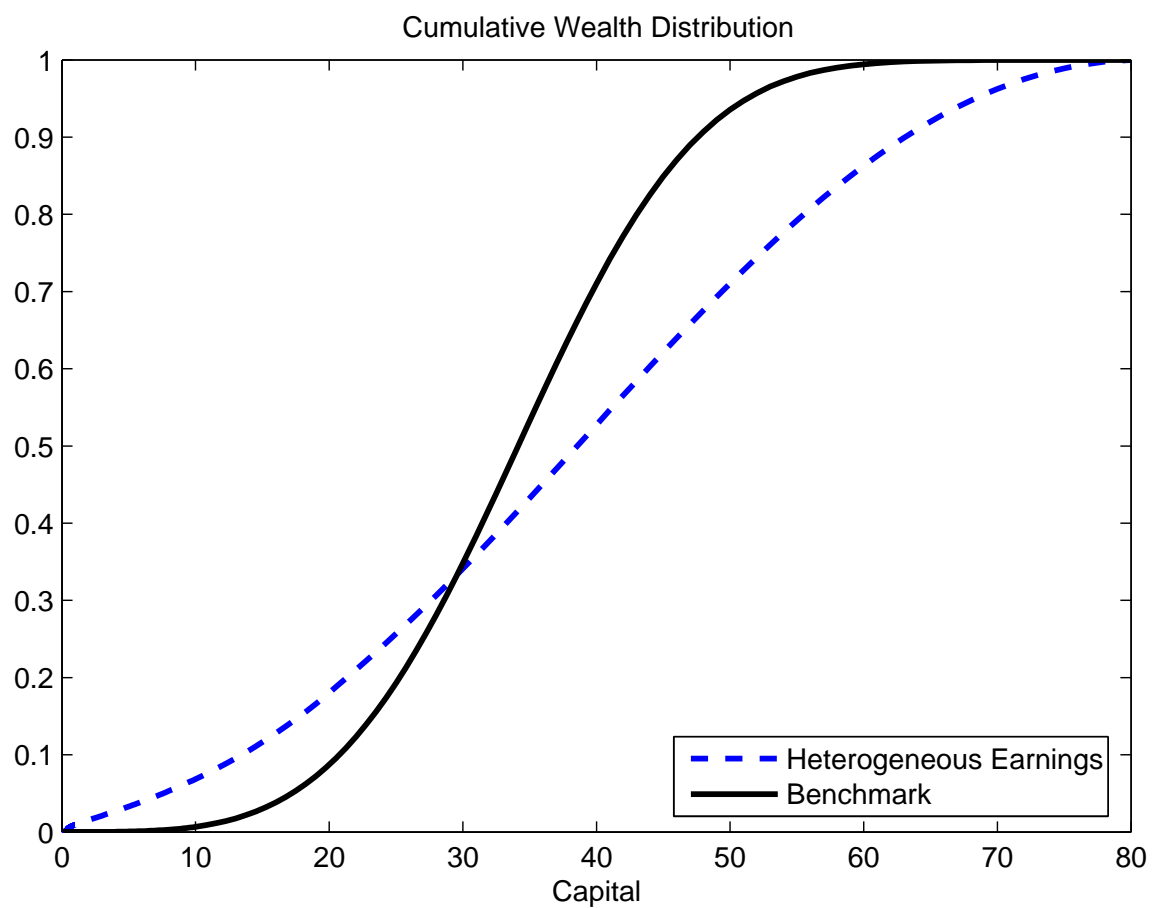

Figure 3: Comparison of the CDFs of asset holdings in the baseline uninsurable risk economy (solid line) versus the economy with idiosyncratic productivity shocks (dotted line). 